\title{
Anti-apoptotic potential of insect cellular and viral IAPs in mammalian cells
}

\author{
Christine J. Hawkins, ${ }^{1,2}$ Paul G. Ekert, ${ }^{1}$ Anthony G. Uren, ${ }^{1}$ \\ Shaun P. Holmgreen ${ }^{1}$ and David L. Vaux ${ }^{1,3}$ \\ 1 The Walter and Eliza Hall Institute for Medical Research, Post Office Royal \\ Melbourne Hospital, Victoria, 3050, Australia \\ 2 Present address: Department of Biology 156-29, California Institute of \\ Technology, 1201 East California Blvd., Pasadena, California 91125, USA \\ ${ }^{3}$ corresponding author: David L. Vaux, The Walter and Eliza Hall Institute for \\ Medical Research, Post Office Royal Melbourne Hospital, Victoria, 3050, \\ Australia. tel: (61) 39345 2544; fax: (61) 39347 0582; \\ email: vaux@wehi.edu.au
}

Received 24.11.97; revised 2.2.98; accepted 26.2.98

Edited by G. Melino

\begin{abstract}
IAPs were identified as baculoviral proteins that could inhibit the apoptotic response of insect cells to infection. Of the viral IAPs, OpIAP and CpIAP can inhibit apoptosis, whereas AcIAP cannot. OpIAP and some mammalian homologues can inhibit mammalian cell death. Two mammalian IAPs bind to TNFRII associated factors (TRAFs), but the significance of this is unclear. Here we show that Drosophila cellular IAPs and two baculoviral IAPs (OpIAP and CpIAP) can inhibit mammalian cell death induced by overexpression of Caspases 1 and 2 . IAPs must act on conserved components of the apoptotic mechanism, but as none of these IAPs could bind TRAF proteins, TRAFs are not likely to be important for IAP mediated apoptosis inhibition. As OpIAP protected against death induced by ligation of TNF receptor family members, but not by factor nor serum withdrawal from dependent cells, it can inhibit certain apoptotic pathways without affecting others.
\end{abstract}

Keywords: IAP; caspase; p35; Drosophila; cytokine; RING finger; programmed cell death

Abbreviations: IAP, inhibitor of apoptosis; BIR, baculovirus IAPlike repeat; TNF, tumor necrosis factor; TRAF, TNF receptorassociated factor; NGF, nerve growth factor; SEM, standard error of the mean; IL3, interleukin-3; GFP, green fluorescent protein; $\mathrm{MIH}$, mammalian IAP homologue; MTT, dimethylthiazol dophenyltetrazolium bromide.

\section{Introduction}

Apoptosis is a physiological process by which unwanted cells are removed (Vaux and Strasser, 1996). It is used in normal circumstances during development and for homeostatic control of cell numbers. Apoptosis is also used as a defence mechanism to remove cells which have been altered in a way which renders them dangerous for the organism as a whole. Intracellular pathogens such as viruses require the host cell's synthetic machinery to replicate, so apoptosis can be used to halt their spread.

The mechanism of apoptosis is highly conserved throughout the metazoa. A family of a cysteine proteases termed caspases (Alnemri et al, 1996) appear to be the key apoptosis effector enzymes in nematodes, insects and mammals. For example, Ced-3, the nematode member of this family, is essential for programmed cell death in the worm Caenorhabditis elegans (Ellis and Horvitz, 1986; Yuan and Horvitz, 1990; Yuan et al, 1993). Several mammalian caspases have been described (reviewed by Alnemri, 1997), many of which trigger apoptosis when overexpressed, and some of which are essential for apoptosis in particular circumstances (Kuida et al, 1995, 1996). Caspases have been identified in insects (Ahmad et al, 1997; Fraser and Evan, 1997; Song et al, 1997), and inhibition of caspase activity in insect cells by baculoviral p35 prevents apoptosis (Bump et al, 1995; Clem et al, 1991).

Many viral anti-apoptosis proteins have been identified that prevent cell death by either inhibiting caspase activity, or blocking pathways that lead to caspase activation. Two types of apoptosis inhibitory molecules have been cloned from baculoviruses. p35 was initially described as a gene deleted from a mutant baculoviral strain for which infection was accompanied by massive cell death (Clem et al, 1991). p35 inhibits apoptosis by binding directly to and thereby inactiving the caspases (Bump et al, 1995; Xue and Horvitz, 1995).

The first members of the IAP family were identified in a search for novel baculoviral anti-apoptotic genes (Crook et al, 1993). These proteins have a carboxy terminal RING finger domain, and at their amino termini are two repeats of a motif designated baculovirus IAP-like repeat (BIR). IAPs from Orgyia pseudotsugata nuclear polyhedrosis virus and Cydia pomonella granulosis virus (OpIAP and CpIAP) could suppress the apoptosis caused by infection of insect cells with p35 deficient viruses (Birnbaum et al, 1994; Crook et al, 1993). Interestingly, a third baculoviral IAP from Autographa californica nuclear polyhedrosis virus (AcIAP) was incapable of inhibiting insect cell death (Birnbaum et al, 1994).

IAPs must interact with conserved components of the apoptotic mechanism, since OpIAP could inhibit death of mammalian cells due to overexpression of caspases, the CD95 signaling molecule FADD, or infection with Sindbis virus (Duckett et al, 1996; Hawkins et al, 1996).

While these experiments did not reveal which components of the apoptotic mechanism were affected by IAPs, they suggested that cellular IAP homologues may exist that regulate apoptosis in host organisms. Two endogenous insect IAPs have been cloned from Drosophila using a screen for repressors of REAPER-induced death in the fly eye (Hay et al, 1995). Lesions in DIAP-1 enhance the cell 
death seen in the eyes of flies with enforced expression of the Drosophila cell death gene rpr. Overexpression of DIAP-1 and a second related gene, DIHA/DIAP-2/dILP prevented insect cell apoptosis triggered during development and by overexpression of the Drosophila cell death proteins REAPER and HID (Hay et al, 1995; Vucic et al, 1997). OpIAP truncation or mutated constructs were previously tested in insect and mammalian cells and the RING finger was found to be essential for optimal protective ability (Clem and Miller, 1994; Hawkins et al, 1996). By contrast, however, a DIAP-1 gene lacking the RING finger gave elevated levels of protection in the Drosophila eye compared to the full length gene (Hay et al, 1995).

Five mammalian IAP genes have been identified. The first, NAIP, a candidate gene for Spinal Muscular Atrophy, has three BIRs but no RING finger (Roy et al, 1995). Three of the other mammalian IAPs, MIHA/hILP/xiap, MIHB/hiap1/c-IAP1 and MIHC/hiap2/c-IAP-2 all have three BIRs and a RING finger (Rothe et al, 1995; Duckett et al, 1996; Liston et al, 1996; Uren et al, 1996). The fifth mammalian IAP, survivin, has a single BIR and no RING finger (Ambrosini et al, 1997). In this paper, the cellular IAPs will be referred to using the $\mathrm{MIH} / \mathrm{DIH}$ nomenclature.

One group identified $\mathrm{MIHB}$ and $\mathrm{MIHC}$ by virtue of their association with TNFRII (Rothe et al, 1995). MIHB and $\mathrm{MIHC}$ interact indirectly with this receptor, via the signaling components TRAF1 and TRAF2 (Rothe et al, 1994). Since many members of the TNFR family of receptors are capable of signaling apoptosis, this interaction raised the possibility that IAPs may prevent apoptosis by modulating signals from them.

Much has been recently discovered about the components of the signal transduction pathways which emanate from these receptors. Signals from TNFRI can lead to activation of caspases and hence apoptosis, theoretically by two alternative sets of interacting molecules. One pathway from the receptor is via TRADD and FADD to Caspase-8 (Muzio et al, 1997; Srinivasula et al, 1996). The other, which involves TRADD, RIP and RAIDD, activates Caspase-2 (Duan and Dixit, 1997). Both TNFRI and TNFRII can signal $\mathrm{NF}_{\kappa} \mathrm{B}$ activation via TRAF2, but this usually has a pro-survival effect (Liu et al, 1996; Rothe et al, 1994).

Cell viability can be regulated by signals from membrane receptors other than the TNF receptor family. For example, many cells require a continuous supply of cytokines for their survival. When growth factors are removed from such cells, they undergo apoptosis. The hemopoietin family of receptors signal via Jak pathways (reviewed by Ihle, 1996) but the way that factor deprivation results in cell death is not known.

Apoptosis due to loss of signals from hemopoietin receptors is often efficiently blocked by members of the $\mathrm{Bcl}-2$ family of apoptosis inhibitors (Vaux et al, 1988), whereas in most cell types killing by TNF is relatively poorly blocked by $\mathrm{Bcl}-2$ and its relatives (Huang et al, 1997; Strasser et al, 1995).

In an attempt to more fully characterize the cell deathinhibitory actions of the IAP family, we have compared the ability of baculoviral and endogenous insect members of the IAP family to suppress mammalian cell death induced by caspase overexpression, and explored the range of mammalian apoptotic stimuli against which one family member, OpIAP, can function. We have also assessed the ability of DIAP-1 and DIHA genes (both full length and lacking the RING domain) to prevent mammalian apoptosis, and tested endogenous and viral insect IAPs for their ability to bind TRAF proteins.

\section{Results}

\section{Protection against mammalian cell death by baculoviral IAPs}

To determine if the antiapoptotic activity of OpIAP, CpIAP and AcIAP in mammalian cells reflected their activity in insect cells, we tested their ability to protect against death induced by transient expression of Caspase-1 and Caspase-2 in HeLa cells using the caspase-lacZ fusion protein overexpression system described previously (Miura et al, 1993; Hawkins et al, 1996) (Figure 1). As in insect cells, OpIAP and CpIAP were able to promote survival, whereas AcIAP was not. Although these results do not indicate whether AcIAP will be able to inhibit apoptosis in some other system, they lend support to the notion that the targets of OpIAP and CpIAP have been highly conserved during evolution.

\section{Analysis of anti-apoptotic potential of full length and truncated Drosophila IAPs in mammalian cells}

When overexpressed in the eye, the two Drosophila IAPs protect insect cells from developmental death and that induced by overexpression of REAPER and HID (Hay et al, 1995). To determine whether, like the insect virus genes, they could function in mammalian cells, HeLa cells were cotransfected with the Casp-1/lacZ expression vector (Miura et al, 1993) and a plasmid expressing DIAP-1 or DIHA, or controls. Figure 2 shows that both of the Drosophila IAPs were capable of suppressing apoptosis induced by overexpression of Caspase-1.

Experiments in insect cells have shown that substitution of either the BIRs or the RING finger of OpIAP with those from AclAP abolishes their protective ability (Clem and Miller, 1994). This suggests that both the BIRs and the RING finger domain of IAPs are required for activity. Consistent with this idea, removal of the RING finger of OpIAP also abolished its protective potential in mammalian cells. (Duckett et al, 1996; Hawkins et al, 1996). In the context of the Drosophila eye, however, a truncated DIAP1 lacking its RING finger domain functioned more effectively than wild type to inhibit developmental, HID and REAPER induced death (Hay et al, 1995).

As it was unclear whether these different requirements for the RING finger domain reflected different actions of particular IAP proteins, or was due to differences in the cellular contexts in which they had been tested, we compared them directly using the same assay in which the deleted OpIAP construct was inactive (Hawkins et al, 1996). 
As shown in Figure 2, removal of the RING finger from either of the Drosophila IAPs decreased the efficacy of their protection, with DIAP1 being more strongly affected than DIHA. These results are consistent with a model in which the BIRs are the key functional parts of the IAP proteins, but the requirement for the RING finger domain is only partial, and depends on the cellular context.

\section{Determination of the range of apoptotic stimuli inhibited by OpIAP}

Ligation of TNF and CD95 receptors OpIAP was the most efficient inhibitor of apoptosis in the assays we had performed previously (Hawkins et al, 1996; Uren et al, 1996), so it was chosen to determine which apoptotic signaling pathways utilize components which are susceptible to IAP inhibition. MCF-7 mammary carcinoma cells were transfected with a vector bearing the lacZ gene and either empty vector, p35 or OpIAP plasmids. Following transfection, the cells were either incubated with normal medium or treated with TNF at two doses, for either $24 \mathrm{~h}$ (Figure $3 \mathrm{~A}$ ) or $48 \mathrm{~h}$ (Figure 3B). The viability of the $\beta$-galactosidase positive cells was then scored. As shown in Figure 3, both p35 and OpIAP conferred substantial protection against TNF-mediated death in this cell line.

A subline of HeLa cells, which die in response to ligation of CD95, were used to assess whether OpIAP could inhibit apoptosis triggered in this way. Cells
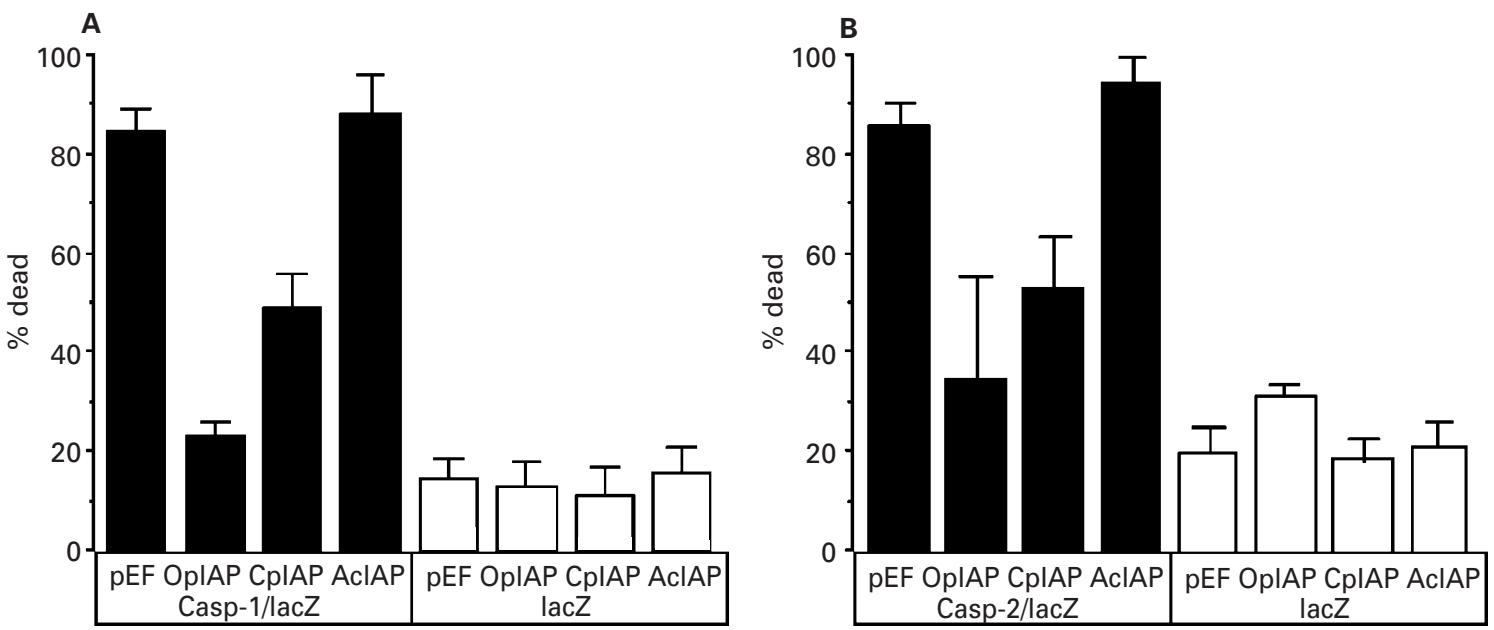

Figure 1 OpIAP and CpIAP but not AcIAP can prevent mammalian cell death induced by overexpression of Caspass 1 and 2 . HeLa cells were transiently transfected with coded transfection mixtures of lipofectamine with either Casp-1/lacZ (A) or Casp-2/lacZ plasmids (B) and pEF with either no insert, or the coding regions of OpIAP, CpIAP or AcIAP. Parallel transfections were performed using the lacZ only plasmid insted of the caspase/lacZ fusion plasmids to assess background cell death casued by the transfection procedure. After $18 \mathrm{~h}$ the cells were fixed, stained and scored visually for viability. As in all Figures, error bars represent two standard errors of the mean (S.E.M.)
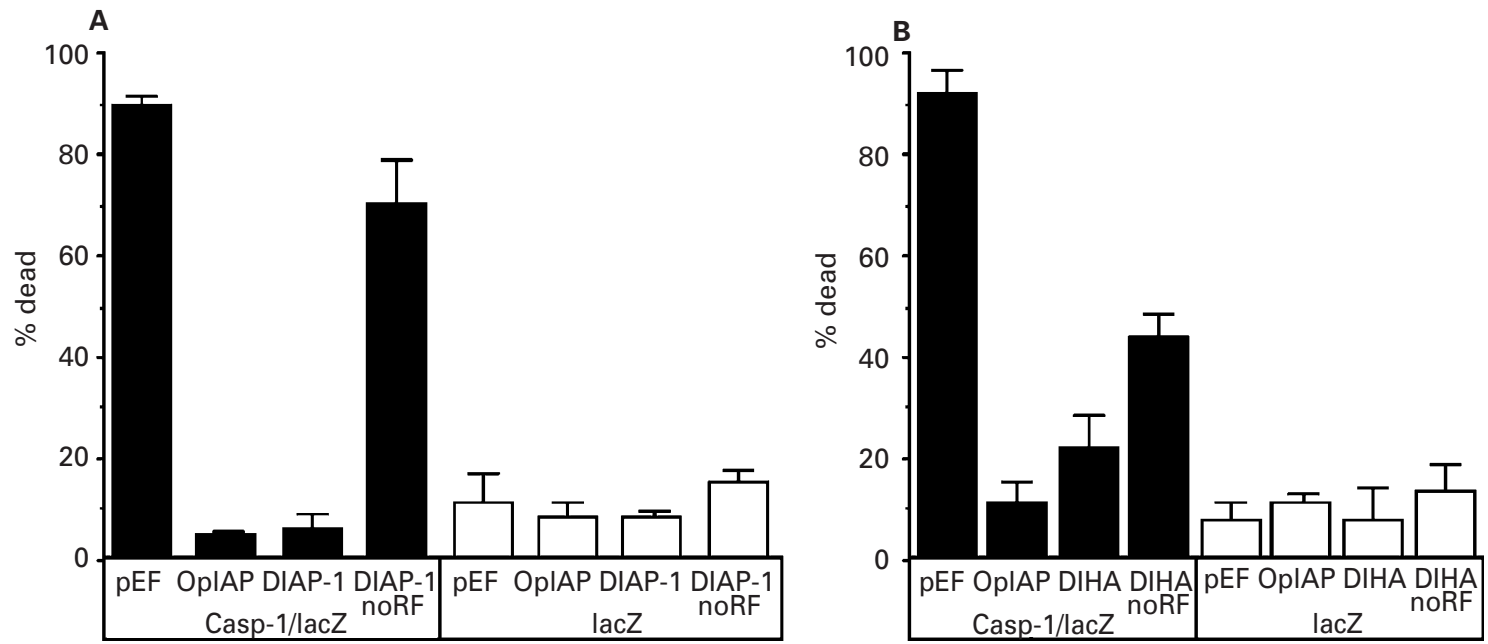

Figure 2 DIAP1 and DIHA can prevent mammalian cell death induced by Caspase-1, and truncated forms lacking the RING finger are less potent than full length genes. HeLa cells were transfected with Casp-1/lacZ and pEF vector containing either no insert, OpIAP or full length or truncated DIAP1 (A), or full length or truncated DIHA (B). Parallel transfections were performed using the lacZ plasmid instead of the caspase fusion plasmids to assess background cell death. After $18 \mathrm{~h}$ the cells were fixed, stained and scored. Error bars represent $2 \times$ S.E.M. 

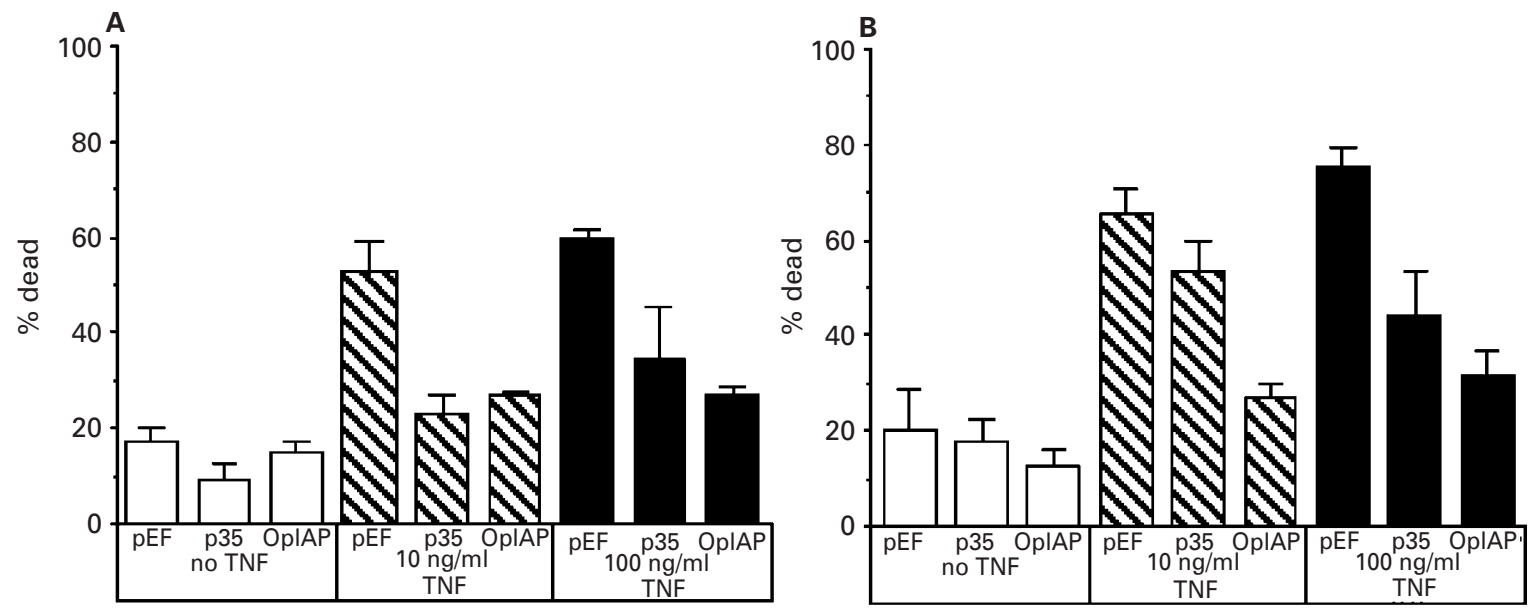

Figure 3 OpIAP can prevent TNF mediated mammalian cell death. MCF7 cells were transiently transfected with lacZ plasmid and pEF vector containing either no insert, p35 or OpIAP. After $18 \mathrm{~h}$ the medium was replaced with medium containing either no TNF, $10 \mathrm{ng} / \mathrm{ml}$ or $100 \mathrm{ng} / \mathrm{ml} \mathrm{TNF}$. After a further $24 \mathrm{~h}$ (A) or $48 \mathrm{~h}(\mathbf{B})$, the cells were fixed, stained and scored for viability. Error bars represent $2 \times$ S.E.M.

transfected with plasmids encoding lacZ and apoptosis inhibitors were incubated for $48 \mathrm{~h}$ either with normal medium or medium containing anti-Apo-1 antibody. The $\beta$-galactosidase positive cells were then scored for viability. While most of the cells transfected with empty vector died, the cells transfected with plasmids encoding p35 survived (Figure 4). Cells receiving the OpIAP plasmid exhibited increased survival compared to the control cells, but this protection was not as efficient as that conferred by p35.

Factor or serum withdrawal The myeloid FDC-P1 cell line, which is dependent on IL-3 or GM-CSF for survival (Dexter et al, 1980) was used to test the ability of OpIAP to inhibit death induced by factor starvation. For these experiments, clonal lines stably expressing OpIAP were generated. Levels of expression were determined by Northern blot (Figure 5A).

As shown in Figure 5B, all of the OpIAP expressing lines died when cultured in the absence of IL-3. Furthermore, the rate of cell death was the same as for the parental cells and a Bax-expressing line. OpIAP must target a different apoptosis pathway to $\mathrm{Bcl}-\mathrm{w}$, as this $\mathrm{Bcl}-2$ family protein was able to confer significant protection against growth factor withdrawal (Gibson et al, 1996).

The neuronal cell line PC12 was used to investigate the ability of OpIAP to inhibit apoptosis induced by serum starvation. When undifferentiated, these cells die in response to serum withdrawal, as shown in Figure 6. Cells were cotransfected with either the empty vector (pEF), or plasmids encoding apoptosis inhibitors, together with a Green Fluorescent Protein (GFP) vector as a marker of transfection. The green cells were sorted by flow cytometry and cultured for 2 days in medium either containing or lacking serum. The number of viable cells was then determined by an MTT assay, which stains cells with active mitochondria (Figure 6). Bcl-2 and (to a lesser extent) p35 protected PC12 cells from this apoptotic

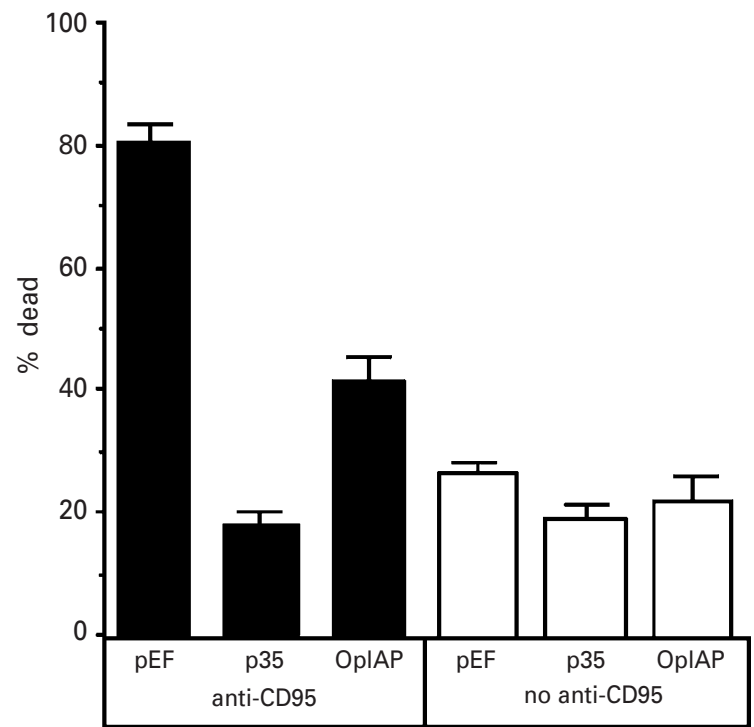

Figure 4 OpIAP inhibits CD95-mediated apoptosis. HeLa cells were transfected with lacZ plasmid together with $\mathrm{pEF}$ vector containing either no insert, p35 or OpIAP. After $18 \mathrm{~h}$ the medium was replaced with either normal medium, or medium containing anti-CD95 antibody at $1 \mu \mathrm{g} / \mathrm{ml}$. After a further $48 \mathrm{~h}$ the cells were fixed, stained and scored for viability. Error bars represent $2 \times$ S.E.M.

stimulus, as has been previously reported (Mah et al, 1993). OpIAP was not able to protect the cells from death due to serum withdrawal. This suggests that OpIAP interferes with different components of death signaling pathways than p35 and $\mathrm{Bcl}-2$.

\section{TRAF binding}

The finding that two of the mammalian IAPS, MIHB and MIHC, could interact with components of the TNFRII signaling 
machinery hinted that this may be the way by which IAPs inhibit cell death (Rothe et al, 1995). While the finding that OpIAP can inhibit TNF and CD95 mediated death is consistent with this idea, earlier work had shown that neither OpIAP nor MIHA could interact with TRAF1, 2 nor 3 (Uren et al, 1996). To establish whether the other baculoviral IAPs or the Drosophila IAPs could bind to the TRAFs, we analyzed them using the yeast two hybrid system. As shown in Figure 7, unlike MIHB and $\mathrm{MIHC}$, none of the endogenous insect or viral IAPs tested could bind to TRAF1, TRAF2, TRAF3 in yeast.
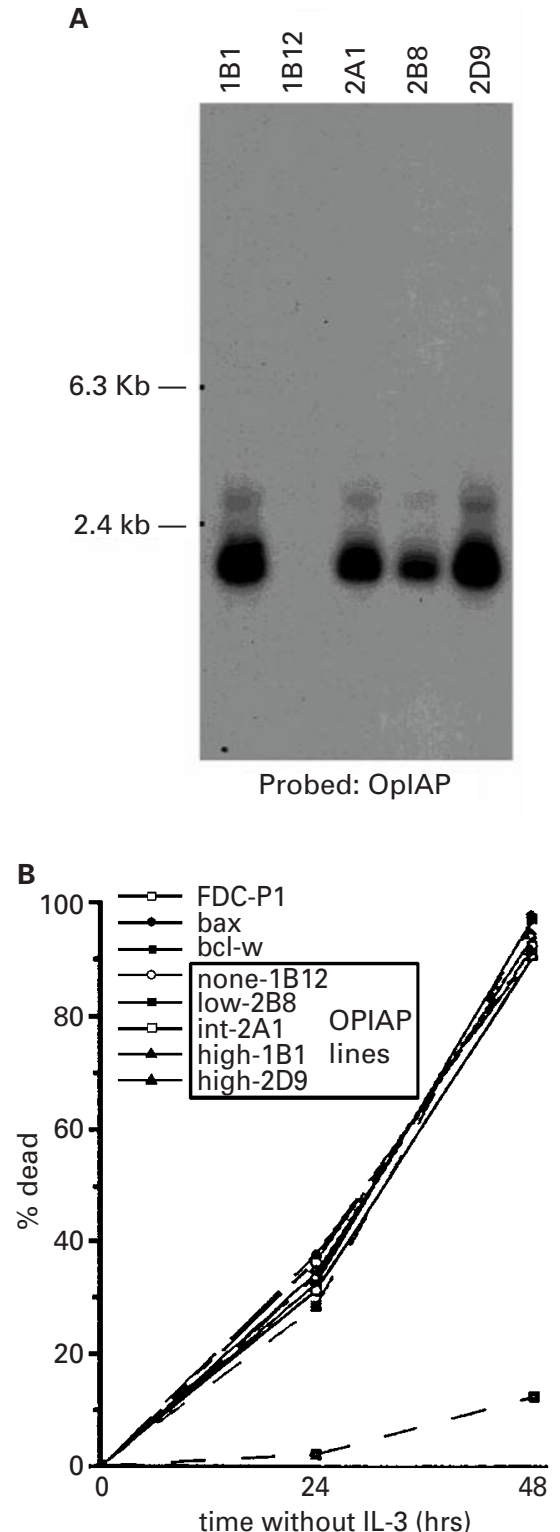

Figure 5 Stable FDC-P1 lines express a range of levels of OpIAP mRNA but were not protected from death induced by factor withdrawal. (A) Northern analysis of total RNA from stable FDC-P1 lines probed with OpIAP. (B) Wildtype FDC-P1 cells or lines stably expressing various levels of OpIAP, Bcl-w or Bax were incubated in medium in the presence or absence of IL-3. The cells assayed for viability at 24 and $48 \mathrm{~h}$ using $\mathrm{PI}$ exclusion followed by flow cytometric analysis

\section{Discussion}

The ability of the insect and baculoviral IAPs to inhibit apoptosis in mammalian cells corresponded to their ability to inhibit the death of insect cells (Birnbaum et al, 1994; Clem and Miller, 1994; Hay et al, 1995; Vucic et al, 1997). This presumably indicates that in these two systems IAPs interfere with homologous components of the apoptosis mechanism.

There has been some controversy regarding the requirement for the RING finger domain of IAPS for their ability to inhibit cell death. Data from experiments using OpIAP, both in insect (Clem and Miller, 1994) and mammalian cells (Hawkins et al, 1996) indicate that the RING finger is required for efficient protection. While we have found that the RING domain of MIHA is necessary for maximal activity (data not shown), Devereaux et al found that the RING finger of MIHA was dispensable for protection against apoptosis induced by expression of Bax (Deveraux et al, 1997). In the context of the Drosophila eye, however, the protective ability of DIAP1 is enhanced by removal of its RING finger domain (Hay et al, 1995).

In this paper we compared protection of full length Drosophila IAPs and the truncated forms lacking the RING fingers. In a system in which truncated OpIAP provided negligible protection, truncated DIAP1 and DIHA proteins (that conferred increased function in the Drosophila eye) gave drastically reduced protection. These results imply that the regulatory effect of the RING finger of the Drosophila IAPs is specific either to the cell type or the stimuli (developmental, irradiation, REAPER and HID overexpression induced death versus caspase overexpression), but is not a property of the proteins themselves. This may signify a difference in the components of the death signal transduction pathway(s) with which the IAPs interact in these situations, or different effects on protein stability of removing the RING domain in different cell types. While the impact of removal of the RING finger differs from system to system, in all cell types examined the BIRs are required for anti-apoptotic activity, indicating that they are the key functional domain of IAP proteins.

OpIAP was able to inhibit some pathways leading to cell death, but not others. In myeloid cells OpIAP was incapable of preventing death induced by IL-3 withdrawal, and in PC12 cells it could not protect against death due to serum starvation. OpIAP did, however, protect MCF7 cells from death caused by exposure to TNF, and was capable of rescuing most transfected HeLa cells from CD95-mediated apoptosis.

Levels of expression of untagged OpIAP in the stable cell lines were determined by Northern blot, as antibodies against OpIAP are not available, and tagged OpIAP proteins have significantly reduced protective ability in caspase overexpression assays (data not shown). Despite our inability to quantify OpIAP protein expression in the FDC-P1 stable cell lines, the vector used to generate these lines does function in other assays, implying that most likely OpIAP protein is present in the FDC-P1 cells, but not protective against factor withdrawal induced death. 

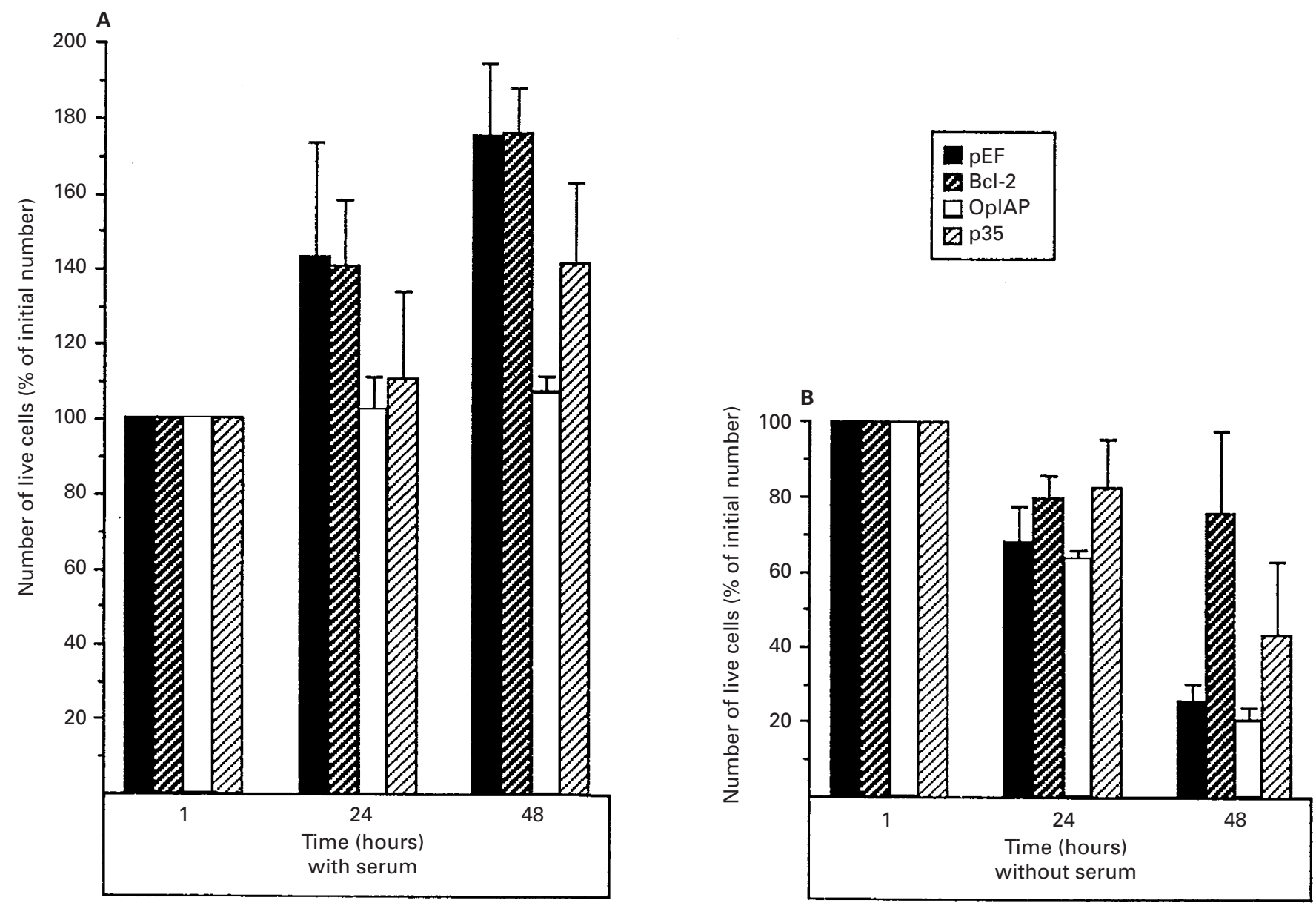

Figure 6 OpIAP does not protect PC12 cells from apoptosis triggered by serum starvation. PC12 cells were transfected with a plasmid expressing GFP along with the $\mathrm{pEF}$ vector with either no insert, p35, Bcl-2 or OpIAP. The green cells were sorted by flow cytometry. The following day they were cultured in medium either containing or lacking serum for 2 days. Viability was assessed by propidium iodide exclusion. Error bars represent $2 \times$ S.E.M.

It is noteworthy that OpIAP behaved differently to Bcl-2 proteins and to p35, perhaps indicating differences either in the mechanisms of action or in specificity for substrates of these molecules. Bcl-2 and its relatives confer substantial protection against factor and serum withdrawal induced death in a variety of cell types (Vaux et al, 1988), but in most cell types offer little protection against apoptosis triggered by ligation of members of the TNF receptor family (Huang et al, 1997; Strasser et al, 1995). Interestingly, mammalian IAPs can prevent death induced by overexpression of the Bcl-2 antagonists Bak, Bik and Bax (Deveraux et al, 1997; Orth and Dixit, 1997). One interpretation of these two sets of data would be that factor withdrawal from dependent cells, although inhibitable by $\mathrm{Bcl}-2$, does not require the action of Bak, Bik nor Bax, and hence cannot be blocked by overexpression of OpIAP. Recently published data from transgenic studies would support this hypothesis (Knudson and Korsemeyer, 1997).

The finding that of the eight IAPs tested to date, only MIHB and MIHC can bind to the TRAFs makes the hypothesis that the IAPs inhibit apoptosis by altering TRAF signaling seem unlikely.
The nature of the mechanism of action of the IAPs remains unresolved. Papers published recently present conflicting evidence on whether IAPs inhibit steps upstream of caspase activation or act downstream to directly bind to and inhibit activated caspases. Manji et al showed that OpIAP was unable to inhibit the active baculoviral host caspase, SfCasp-1 (Manji et al, 1997), whereas subsequent papers concluded that MIHA, B and C (XIAP, c-IAP-1 and C-IAP-2) directly bind and inhibit mammalian caspases 3 and 7 (Deveraux et al, 1997; Roy et al, 1997), but not to caspases 1, 6 or 8 . It seems unlikely that different members of a family of genes so conserved in sequence and function would have different modes of action. It is possible that, as postulated by Deveraux et al, different members may be active against varying subsets of caspases (Deveraux et al, 1997). If this is true, it would argue that OplAP's target in its host is an enzyme other than SfCasp-1. Both OpIAP and MIHA (X-IAP) can inhibit death induced by expression of pro-caspase-1 (Hawkins et al, 1996; Duckett et al, 1996; Uren et al, 1996). As MIHA does not bind to active caspase-1 (Deveraux et al, 1997), it, and by inference OpIAP, are likely to act by preventing signals that activate 

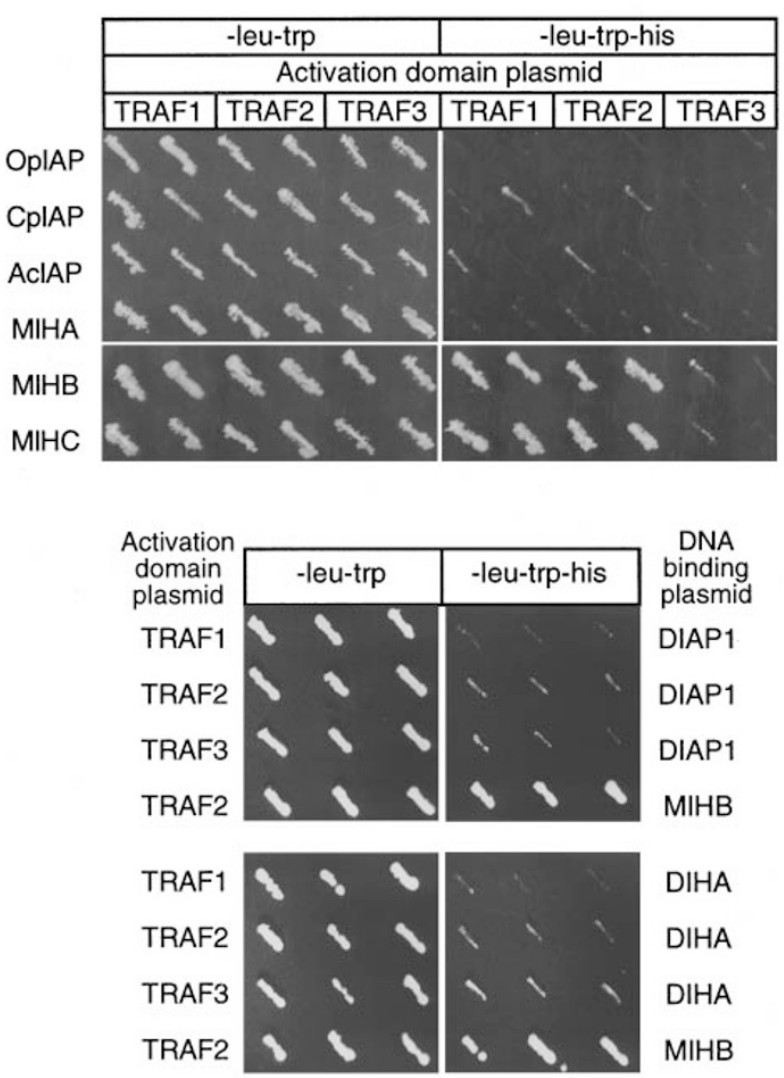

Figure 7 Neither the insect viral nor endogenous IAPs interact with TRAFs 1, 2 and 3 . Yeast were cotransformed with TRAF and IAP plasmids, and the ability of the double transformants to grow on medium lacking histidine was determined. Only yeast containing MIHB or C and TRAF1 or 2 could grow on these plates, indicating that only these pairs of genes encode proteins which interact

pro-caspase-1 or by blocking caspases activated by caspase-1.

The differing ability of OpIAP and p35 to inhibit apoptosis of PC12 cells induced by serum withdrawal suggests that if OpIAP is a caspase inhibitor, it binds to a different set of caspases than p35. If the IAPs act by directly binding to active caspases, their ability to inhibit apoptosis may also depend on their stability and the abundance of the caspase. Differing observations in different cell types may therefore also reflect the stoichiometric ratios of proteins within each cell type.

\section{Materials and Methods}

\section{Constructs}

The cDNAs for OpIAP, CpIAP and AclAP were a gift from Lois Miller (University of Georgia). The TRAF plasmids were provided by Mike Rothe (Tularik Inc). The pEF vector was provided by David Huang (WEHI). The yeast two hybrid system and the vector pGBT9 were from the Matchmaker kit (Clontech). The Casp-1/lacZ (p/actM11Z) and
Casp-2/lacZ ( $\mathrm{p} \beta$ actH37Z) plasmids were provided by Junying Yuan (Harvard) (Miura et al, 1993; Wang et al, 1994).

Details of the $\mathrm{pEF}, \mathrm{pEF}-\mathrm{OpIAP}$ and LacZ plasmids have previously been reported (Hawkins et al, 1996), as have the OpIAP, MIHA, MIHB, MIHC GBT plasmids (Uren et al, 1996).

CpIAP, AcIAP, DIAP1, and DIHA cDNAs were amplified by PCR to generate products bearing mammalian consensus Kozak sequences and $B a m H I$ and $X b a l$ restriction sites to allow subcloning into the vector $\mathrm{pEF}$. For insertion into the yeast vector $\mathrm{pGBT}$, cDNAs were amplified with primers to allow inframe insertion into $\mathrm{EcoRI}$ and $\mathrm{BamHI}$ sites. Primers designed to insert a termination codon after amino acid 381 of DIAP-1 were used to generate DIAP-1noRF and after amino acid 442 of DIHA to generate pEF-DIHAnoRF. Constructs were verified by sequencing. Details of primers used in making these constructs will be provided upon request.

\section{Expression studies}

Yeast two hybrid analysis and lipofectamine mediated transient transfections were performed as described previously (Hawkins et al, 1996). Cells were cultured in RPMI with $10 \%$ FCS unless otherwise specified. All cells were transfected with coded mixtures of lipofectamine (Gibco) and DNA such that scoring of the assays was performed blind. Error bars on the figures represent two standard errors of the mean (S.E.M.). For the caspase death assays, the caspase/lacZ fusion plasmid and the test plasmid or control were transfected in a ratio of $1: 10$ to ensure lacZ positive cells contained the second plasmid.

MCF7 cells were transfected with a 1:10 ratio of lacZ to test plasmid, then 1 day later the medium was replaced with $\mathrm{RPMI} / 10 \%$ FCS with either none, 10 or $100 \mathrm{ng} / \mathrm{ml} \mathrm{TNF}$. Either 24 or $48 \mathrm{~h}$ later the cells were fixed and stained for $\beta$-galactosidase activity using $\mathrm{Xgal}$ as previously described (Hawkins et al, 1996; Miura et al, 1993), and scored visually for viability.

For the CD95 ligation assay, HeLa cells were transfected with a $1: 10$ ratio of lacZ to test plasmid, then 1 day later the medium was replaced with either RPMI $/ 10 \%$ FCS or medium containing $1 \mu \mathrm{g} / \mathrm{ml}$ anti-Apo1 (a kind gift from Peter Krammer). After $48 \mathrm{~h}$ the cells were fixed and scored for viability.

FDC-P1 cells were transfected with the pEF-OpIAP plasmid, and stable clones were selected using puromycin $(2 \mu \mathrm{g} / \mathrm{ml})$. These lines were analyzed by Northern blot to determine the levels of OpIAP. Following culturing in medium either containing or lacking IL-3, the viability of the cells was determined by flow cytometry for exclusion of propidium iodide $(2 \mu \mathrm{g} / \mathrm{ml})$.

PC12 cells were electroporated with a total amount of DNA of $15 \mu \mathrm{g}$, comprising pEGFP-C1 (Clontech) and either empty $\mathrm{pEF}$ vector, pEF-OpIAP, pEF-Bcl-2 or pEF-p35, in a ratio of $1: 10$, then plated in DME with $10 \% \mathrm{FCS}$ and $5 \%$ horse serum for $48 \mathrm{~h}$. The cells were then harvested using trypsin, resuspended in medium containing $2 \mu \mathrm{g} / \mathrm{ml}$ propidium iodide and sorted by flow cytometry for green viable cells. Following overnight culture, the cells were removed using trypsin, washed twice in medium lacking serum, and replated in either DME with serum (10\% FCS $+5 \%$ horse serum) or DME without serum, in Terisaki plates. After 1,24 or $48 \mathrm{~h}$, cell viability was assessed by incubating with MTT for at least $15 \mathrm{~min}$ at $37^{\circ} \mathrm{C}$.

\section{Acknowledgements}

We wish to thank Junying Yuan, Peter Krammer, David Huang, Lois Miller, and Mike Rothe for reagents. This work was supported by a grant to DLV by the Anti-Cancer Council of Victoria. 


\section{References}

Ahmad M, Srinivasula SM, Wang LJ, Litwack G, Fernandes-Alnemri T and Alnemr ES (1997) Spodoptera frugiperda caspase-1, a novel insect death protease that cleaves the nuclear immunophilin FKBP46, is the target of the baculovirus antiapoptotic protein p35. J. Biol. Chem. 272: 1421-1424

Alnemri ES (1997) Mammalian cell death proteases - a family of highly conserved aspartate specific cysteine proteases. J. Biol. Chem. 64: 33-42

Alnemri ES, Livingston DJ, Nicholson DW, Salvesen G, Thornberry NA, Wong WW and Yuan J (1996) Human ICE/CED-3 protease nomenclature. Cell. 87: 171

Ambrosini G, Adida C and Altieri DC (1997) A novel anti-apoptosis gene, survivin, expressed in cancer and lymphoma. Nature Medicine 3: 917-921

Birnbaum MJ, Clem RJ and Miller LK (1994) An apoptosis inhibiting gene from a nuclear polyhedrosis virus encoding a polypeptide with cys/his sequence motif. J. Virol. 68: 2521-2528

Bump NJ, Hackett M, Hugunin M, Seshagiri S, Brady K, Chen P, Ferenz C, Franklin S, Ghayur T, Li P, Licari P, Mankovich J, Shi LF, Greenberg AH, Miller LK and Wong WW (1995) Inhibition of ICE family proteases by baculovirus antiapoptotic protein $\mathrm{p35}$. Science 269: $1885-1888$

Clem RJ, Fechheimer M and Miller LK (1991) Prevention of apoptosis by a baculovirus gene during infection of insect cells. Science 254: 1388-1390

Clem RJ and Miller LK (1994) Control of programmed cell death by the baculovirus genes p35 and IAP. Mol. Cell. Biol. 14: 5212-5222

Crook NE, Clem RJ and Miller LK (1993) An apoptosis inhibiting baculovirus gene with a zinc finger like motif. J. Virol. 67: 2168-2174

Deveraux QL, Takahashi R, Salvesen GS and Reed JC (1997) X-lined IAP is a direct inhibitor of cell-death proteases. Nature 388: 300-304

Dexter TM, Garland J, Scott D, Scolnick E and Metcalf D (1980) Growth factordependent hemopoietic precursor cell lines. J. Exp. Med. 152: 1036-1047

Duan $\mathrm{H}$ and Dixit VM (1997) RAIDD is a new death adaptor molecule. Nature 385 : $86-89$

Duckett CS, Nava VE, Gedrich RW, Clem RJ, Vandongen IL, Gilfillan MC, Shiels H, Hardwick JM and Thomspon CB (1996) A conserved family of cellular genes related to the baculovirus IAP gene and encoding apoptosis inhibitors. EMBO J. 15: $2685-2694$

Ellis HM and Horvitz HR (1986) Genetic control of programmed cell death in the nematode $C$. elegans. Cell 44: 817-829

Fraser AG and Evan GI (1997) Identification of a Drosophila melanogasterICE/CED3-related protease, drICE. EMBO J. 16: 2805-2813

Gibson L, Holmgreen SP, Huang D, Bernand O, Copeland NG, Jenkins NA, Sutherland GR, Baker E, Adams JM and Cory S (1996) Bcl-w, a novel member of the Bcl-2 family, promotes cell survival. Oncogene 13: 665-675

Hawkins CJ, Uren AG, Hacker G, Medcalf RL and Vaux DL (1996) Inhibition of interleukin-1-beta converting enzyme-mediated apoptosis of mammalian cells by baculovirus IAP. Proc. Natl. Acad. Sci. USA 93: 13786-13790

Hay BA, Wassarman DA and Rubin GM (1995) Drosophila homologs of baculovirus inhibitor of apoptosis proteins function to block cell death. Cell 83: 1253-1262

Huang D, Cory S and Strasser A (1997) Bcl-2, Bcl-x(1) and adenovirus protein E1b19kD are functionally equivalent in their ability to inhibitcell death. Oncogene 14: $405-414$

Ihle JN (1996) Janus kinases in cytokine signalling. Philosophical Transactions of the Royal Society of London. Series B: Biological Sciences 351: 159-166

Knudson CM and Korsemeyer SJ (1997) Bcl-2 and Bax function independently to regulate cell death. Nature Genetics 16: 358-363

Kuida K, Lippke JA, Ku G, Harding MW, Livingston DJ, Su MS and Flavell RA (1995) Altered cytokine export and apoptosis in mcie deficient in interleukin-1 beta converting enzyme. Science 267: 2000-2003

Kuida K, Zheng TS, Na SQ, Kuan CY, Yang D, Karasuyama H, Rakic P and Flavell RA (1996) Decreased apoptosis in the brain and premature lethality in CPP32deficient mice. Nature 384: 368-372

Liston P, Roy N, Tamai K, Lefebvre C, Baird S, Chertonhorvat G, Farahani R, Mclean M, Ikeda JE, Mackenzie A and Korneluk RG (1996) Suppression of apoptosis in mammalian cells by NAIP and a related family of IAP genes. Nature 379: 349 353
LiuZG, Hsu HL, Goeddel DV and Karin M (1996) Dissection of TNF receptor 1 effector functions - JNK activtion is not linked to apoptosis while NF-kappa-b activation prevents cell death. Cell 87: 565-576

Mah SP, Zhong LT, Liu Y, Roghani A, Edwards RH and Bredesen DE (1993) The protooncogene Bcl-2 inhibits apoptosis in PC12 cells. J. Neurochem. 60: 11831186

Manji GA, Hozak RR, Lacount DJ and Friesen PD (1997) Baculovirus inhibitor of apoptosis functions at or upstream of the apoptotic suppressor p35 to prevent programmed cell death. J. Virol. 71: 4509-4516

Miura M, Zhu H, Rotello R, Hartweig EA and Yuan J (1993) Induction of apoptosis in fibroblasts by IL-1 $\beta$-converting enzyme, a mammalian homolog of the $C$. elegans cell death gene ced-3. Cell 75: 653-660

Muzio M, Salvesen GS and Dixit VM (1997) FLICE induced apoptosis in a cell-free system - cleavage of caspase zymogens. J. Biol. Chem. 272: 2952-2956

Orth R and Dixit VM (1997) Bik and bak induce apoptosis downstream of crmA but upstream of inhibitor of apoptosis. J. Biol. Chem. 272, 8841-8844

Rothe M, Pan MG, Henzel WJ, Ayres TM and Goeddel DV (1995) The TNFR2-TRAF signaling complex contains two novel proeins relted to baculoviral-inhibitor of apoptosis proteins. Cell 83: 1243-1252

Rothe M, Wong SC, Henzel WJ and Goeddel DV (1994) A novel family of putative signal transducers associated with the cytoplasmic domain of the $75 \mathrm{kDa}$ tumor necrosis factor receptor. Cell 78: 681-692

Roy N, Deveraux QL, Takahashi R, Salvesen GS and Reed JC (1997) The c-IAP-1 and C-IAP-2 proteins are direct inhibitors of specific caspases. EMBO J. 16: $6914-6925$

Roy N, Mahadevan MS, Mclean M, Shutler G, Yaraghi Z, Farahani R, Baird S, Besnerjohnston A, Lefebvre C, Kang XL, Salih M, Aubry H, Tamai K, Guan XP, loannou P, Crawford TO, Dejong PJ, Surh L, Ikeda JE, Korneluk RG and Mackenzie A (1995) The gene for neuronal apoptosis inhibitory protein is partially deleted in individuals with spinal muscular atrophy. Cell 80: 167-178

Song Z, McCall K and Steller H (1997) DCP-1, a Drosophila cell death protease essential for development. Science 275: 536-540

Srinivasula SM, Ahmad M, Fernandes-Alnemri T, Litwack G and Alnemri ES (1996) Molecular ordering of the fas-apoptotic pathway - the Fas/APO-1 protease $\mathrm{MCH} 5$ is a crmA-inhibitable protease that activates multiple Ced-3/ICE-like cysteine proteases. Proc. Natl. Acad. Sci. USA 93: 14486-14491

Strasser A, Harris AW, Huang D, Krammer PH and Cory S (1995) Bcl-2 and Fas/APO1 regulate distinct pathways to lymphocyte apoptosis. EMBO J. 14:6136-6147

Uren AG, Pakusch M, Hawkins CJ, Puls KL and Vaux DL (1996) Cloning and expression of apoptosis inhibitory protein homologs that function to inhibit apoptosis and/or bind tumor necrosis factor receptor-associated factors. Proc. Natl. Acad. Sci. USA 93: 4974-4978

Vaux DL, Cory S and Adams JM (1988) Bcl-2 gene promotes haemopoietic cell survival and cooperates with c-mycto immortalize pre-B cells. Nature 335: 440 442

Vaux DL and Strasser A (1996) The molecular biology of apoptosis. Proc. Natl. Acad. Sci. USA 93: 2239-2244

Vucic D, Seshagiri S and Miller LK (1997) Characterization of reaper- and FADDinduced apoptosis in a lepidopteran cell line. Mol. Cell. Biol. 17: 667-676

Wang L, Miura M, Bergeron L, Zhu H and Yuan J (1994) Ich-1, an ICE/ced-3-related gene, encodes both positive and negative regulators of programmed cell death Cell 78: $739-750$

Xue D and Horvitz HR (1995) Inhibition of the Caenorhabditis elegans cell-death protease Ced-3 by a Ced-3 cleavage site in baculovirus p 35 protein. Nature 377 : $248-251$

Yuan JY and Horvitz HR (1990) The Caenorhabditis elegans genes ced-3and ced-4 act cell autonomously to cause programmed cell death. Devel. Biol. 138: 33-41

Yuan JY, Shaham S, Ledoux S, Ellis HM and Horvitz HR (1993) The C. elegans cell death gene ced 3 encodes a protein similar to mammalian interleukin-1-beta converting enzyme. Cell 75: 641-652 